\title{
IMMUNOHISTOCHEMICAL EXPRESSION OF HARD TISSUE Related Factors in the Mouse Dental Pulp after Immediate TeETh SEParation
}

\author{
A. Nabeyama ${ }^{1,4}$, K. Nakano ${ }^{1}$, S. Saito ${ }^{2}$, M. Sato ${ }^{4}$, N. Okafuji ${ }^{3}$, A. Yamamoto ${ }^{2,4}$, E. Kasahara ${ }^{4}$, \\ T. Kawakami ${ }^{1}$

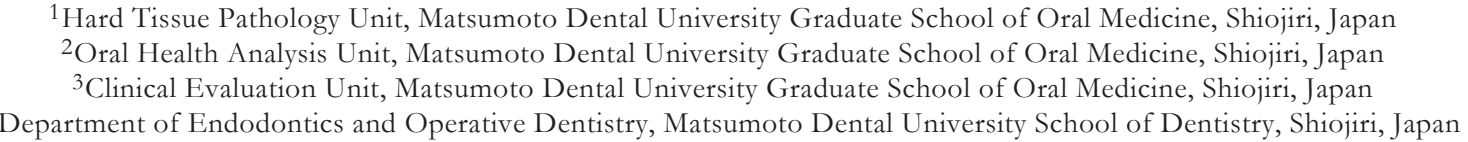

\begin{abstract}
We examined change of Runx 2 and ALP expression in mouse tooth pulp which exposed to teeth separation experiment by immunohistochemistry as a model for conservative dentistry treatment. 8-week-old 36 male ddY mice were used and wedge was inserted between upper 1 st and 2 nd molars. The wedge was removed 30 minutes as well as 3 hours after the insertion and the samples were prepared extending up to 1 week of time period for regular histopathological and immunohistochemical examinations for ALP and Runx 2 expression. The opposite sides without wedge insertion were taken as controls. In the control group pulp, weak expressions of Runx 2 and ALP in the vessel endothelial cells as well as the pulp cells were revealed, suggesting the appearance of these genes upon mechanical stress induced by mastication and tongue pressure etc. On the other hand in the experiment group, Runx2 expression increased both in 30minute and 3-hour teeth separation group. The expression became maximum at 24 hours. Then it gradually decreased and became similar level with the control group at 1 -week after the wedge insertion. Similarly ALP expression increased after the wedge insertion and was maximum at 24 hours and then gradually decreased to the levels similar with the control group. These results suggest that when immunohistochemical expression of Runx 2 as well as ALP was used as an index, no severe damage occur upon clinical application of wedge insertion.
\end{abstract}

Key words: Runx2, ALP, Mechanical stress, Immediate teeth separation, Dental pulp

\section{INTRODUCTION}

The dental pulp generally receives quite strong stimulations from occlusal pressure, food debris impaction, caries induction and tooth fracture and the cells as well as the tissue gives reaction. And also it is well known that the tooth receives considerable stimulation during treatment such as cavity preparation.
For example increase of Runx2 expression [1] during cavity preparation and enhancement of ALP expression during heat stimulation of culture cells [2] have been reported. In conservative dentistry clinics, teeth separation is sometimes applied for restoration of contact points during composite resin repair for caries. In this application, it can be easily imagined that severe mechanical stress is applied to the periodontal tissues in the tooth root. Similarly it has also been shown alteration of expression of hard tissue related molecules and regulatory factors etc. such as BMP and Runx2 in periodontal tissues exposed to mechanical stress during orthodontic treatment [3-9]. The pulp vessels and nerves pass through apical foramen and also side branches exist around the periodontal tissue. Mechanical stress is considered to be transmitted to the pulp cells where it meets with periodontal tissues. In a preliminary study, we focused on hard tissue related factors in the pulp and obtained highly interesting results [10]. In the current study, we examined alterations of ALP as well as Runx2 expressions in the pulp tissue exposed to mechanical stress after wedge insertion by histopathology and immunohistochemistry.

\section{Materials AND Methods}

\section{1) Experimental Animals}

Thirty-six 8-week-old ddY male mice with a weight of $35 \pm 5 \mathrm{~g}(30 \sim 40 \mathrm{~g})$ were obtained from Japan SLC Co. Ltd. (Hamamatsu, Japan). The animals were raised in an environment of $24 \pm 1^{\circ} \mathrm{C}$ in a plastic cage covered with bedding (Paper clean: PEPARLET CO., LTD., Shizuoka, Japan). The animals freely accessed the water and solid food (Picolab Rodent Diet 20: Japan SLC Inc., Hamamatsu, Japan).

\section{2) Experiment Methods}

Anesthesia of the animals were done with gas inhalation (4\% in preanesthesia) of a mixture of isoflurane (Isoflu: Dainippon Sumitomo Pharma Co., Osaka, 


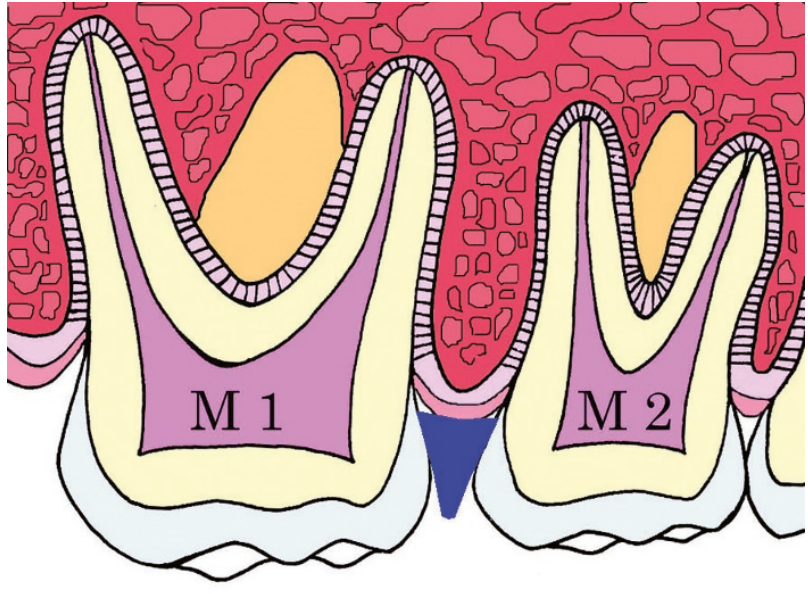

Fig. 1. Diagram of wedge insertion part (arrowhead=wedge).

Japan) and air. A system specific for small animal experiments (Farmer Biometrical Ltd., Laboratory, Osaka, Japan) were used. The mouse was fixed from upper side using a string and from lower side using rubber and its mouth was kept open on the hand made experiment table. The isoflurane inhalation anesthesia and its maintenance were performed through mouse nose. Under the mouse open mouth condition, a wedge (Anatomical WIZARD WEDGES: Water Pik, Inc. Ft. Collins, Colorad, U.S.A) was inserted between the upper right first (M1) and second (M2) molars from palatine side to provide teeth separation (Fig. 1). Mouse has 3 molars in the upper chin and each of the first and second molars has 3 roots. The third molar can have 2 or 3 roots. The experiment groups were divided into groups with 30 minutes and 3 hours of teeth separation time. After each time, the wedge was removed. The samples were collected at the times of $0,3,9,24$ hours, 3 days and 1 week after wedge removal. Thus depending on the time periods, the experiment animals were divided into 6 groups and a total 13 groups were prepared including the controls. The sample numbers in each group are shown in Table 1. The sample collection was done by removing the upper molar tooth part including the periodontal tissues as a whole under the same anesthesia conditions mentioned above. As controls, the opposite side molars (left upper molars) was used with the same method. For observation part, distal buccal root of the upper first molar was used, which is considered to receive highest mechanical stress. The current experiment was performed under the guidelines for use of experimental animals with permission of animal ethical committee of Matsumoto Dental University.
3) Histopathological and Immunohistochemical EXAMINATION

For fixation, the samples were soaked in $4 \%$ paraformaldehyde $0.05 \mathrm{M}$ phosphate buffer solution at $4{ }^{\circ} \mathrm{C}$ for 24 hours. The samples were then decalcified in $10 \%$ EDTA for 3 weeks, followed by paraffin embedding. Then the $4 \mu \mathrm{m}$ continuous horizontal sections were prepared for histopathological and immunohistochemical staining. For immunohistochemical staining, the samples were deparaffinized with xylene after incubation at $60{ }^{\circ} \mathrm{C}$ for 3 hours. For immunohistochemical evaluation, Dako Envision + Kit (K4006-Dako, Glostrup, Denmark) was used. As first antibodies, Rabbit polyclonal Runx2 antibody (Runx2 [M-70] : SC-10758, 1:5000, Santa Curuz Biotechnology, Inc, CA, USA) and Mouse monoclonal ALP antibody (ALP [B4-78] : MAB1448, 1:5000, R\&D Systems, Inc, MN, USA) were used. Counter staining was done with hematoxylen. The controls were also examined with the same protocol except that PBS was used as a first antibody.

\section{RESULTS}

\section{1) Histopathological Examination}

\section{Control Group}

At transverse section of distal buccal side of the upper left first molar root, overlapped odontoblasts attach to dentin and at the center, pulp cells and capillaries between the cells were observed. Also relatively large congested vessels were observed.

\section{Experiment Group}

Odontoblasts were similarly arranged as piling on the dentine and congested capillaries between pulp cells at the center were seen.

\section{2) Immunohistochemical Staining}

Runx2

Control Group

Weak expression of Runx2 was observed in cytoplasms of odontoblasts, pulp cells and vessel endothelial cells of the distal buccal side of the upper left first molar (Figs. 2a,b).

\section{Experiment Group \\ Group with 30 minutes of teeth separation}

Just after removal of wedge, weak expression of Runx2 was observed in cytoplasm of some of the odontoblasts, endothelial cells of the vessels and pulp cells. However, most odontoblasts were negative for Runx2 (Fig. 3a). At 3 hours and 9 hours after wedge

Table 1. Experimental Periods and Number of Specimens.

\begin{tabular}{lc|cccccc|c}
\hline & & min & 3 hrs & 9 hrs & 24 hrs & 3 days & 1week & Total \\
\hline \multirow{2}{*}{$\begin{array}{l}\text { Experimental } \\
\text { Control }\end{array}$} & $30 \mathrm{~min}$ & 3 & 3 & 3 & 3 & 3 & 3 & 18 \\
\hline
\end{tabular}



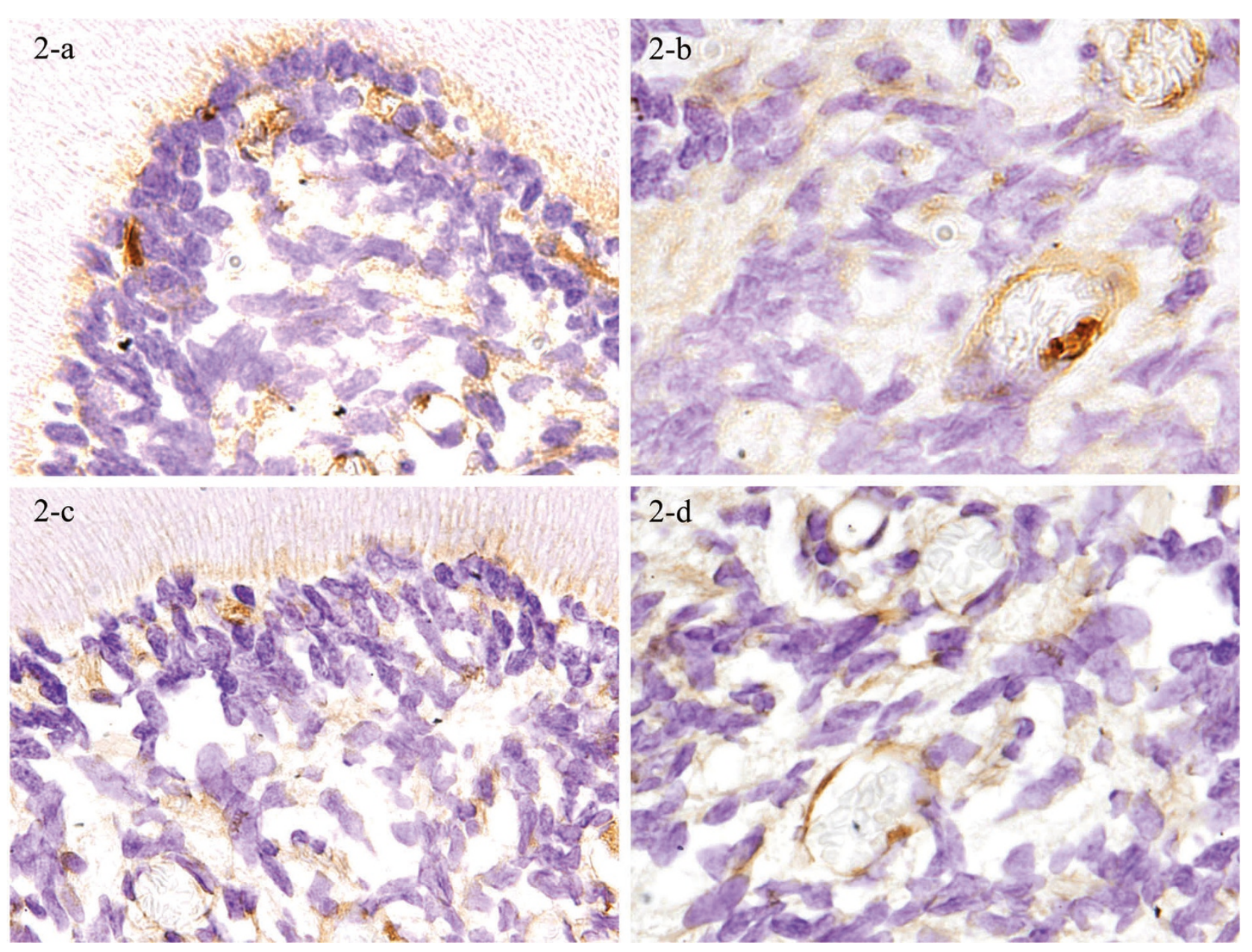

Fig. 2. Runx 2 expression in the control group. Odontoblasts (a) and pulp cells (b) (magnification $x$ 300). ALP expression in the control group. Odontoblasts (c) and pulp cells (d) (magnification x 300).

removal, odontoblasts number for Runx2 staining was increased. Runx2 expression especially increased in cytoplasms of pulp cells and vessel endothelial cells. At 24 hours after wedge removal, more increase of Runx2 expression in cytoplasms of odontoblasts, pulp cells and vessel endothelial cells were observed (Fig. 3b). At 3 days after wedge removal, though Runx2 expressed in cytoplasms of odontoblasts, pulp cells and vessel endothelial cells, the expression became weaker as compared to 24 hours staining. At 1 week after wedge removal, though Runx2 expression was seen in some of cytoplasms of odontoblasts, pulp cells and vessel endothelial cells, the expression became further weaker.

\section{Group with 3 hours of teeth separation}

At just after wedge removal, Runx2 expression was seen in some of odontoblast cytoplasm. Runx2 was especially expressed in cytoplasms of pulp cells and vessel endothelial cells (Fig. 3c). At 3 hours after wedge removal, Runx2 expression became stronger in cytoplasm of odontoblasts and especially in cytoplasms of pulp cells and vessel endothelial cells (Fig. 3d). At 9 hours after wedge removal, Runx2 expression became stronger in cytoplasm of odontoblasts and pulp cells and especially in cytoplasms of vessel endothelial cells (Fig. 3d). At 24 hours after wedge removal, further increase of Runx 2 expression in cytoplasms of odontoblasts, pulp cells and vessel endothelial cells were observed (Fig. 3e). At 3 days after wedge removal, though Runx 2 expression was seen in cytoplasms of odontoblasts, pulp cells and vessel endothelial cells, the expression became weaker as compared to 24 hours staining. At 1 week after wedge removal, though Runx2 expression was seen in some of cytoplasms of odontoblasts, pulp cells and vessel endothelial cells, the expression almost disappeared (Fig. 3f).

\section{ALP}

Control Group

Weak expression of ALP were observed in cytoplasms of some of odontoblasts, pulp cells and vessel endothelial cells of the distal buccal side of the upper left first molar (Fig. 2c,d).

\section{Experiment Group}

Group with 30 minutes of teeth separation

Just after removal of wedge, expression of ALP was observed in cytoplasm of some of the odontoblasts, endothelial cells of the vessels and some of pulp cells. At 3 hours after wedge removal, ALP expression 
$3-\mathrm{a}$
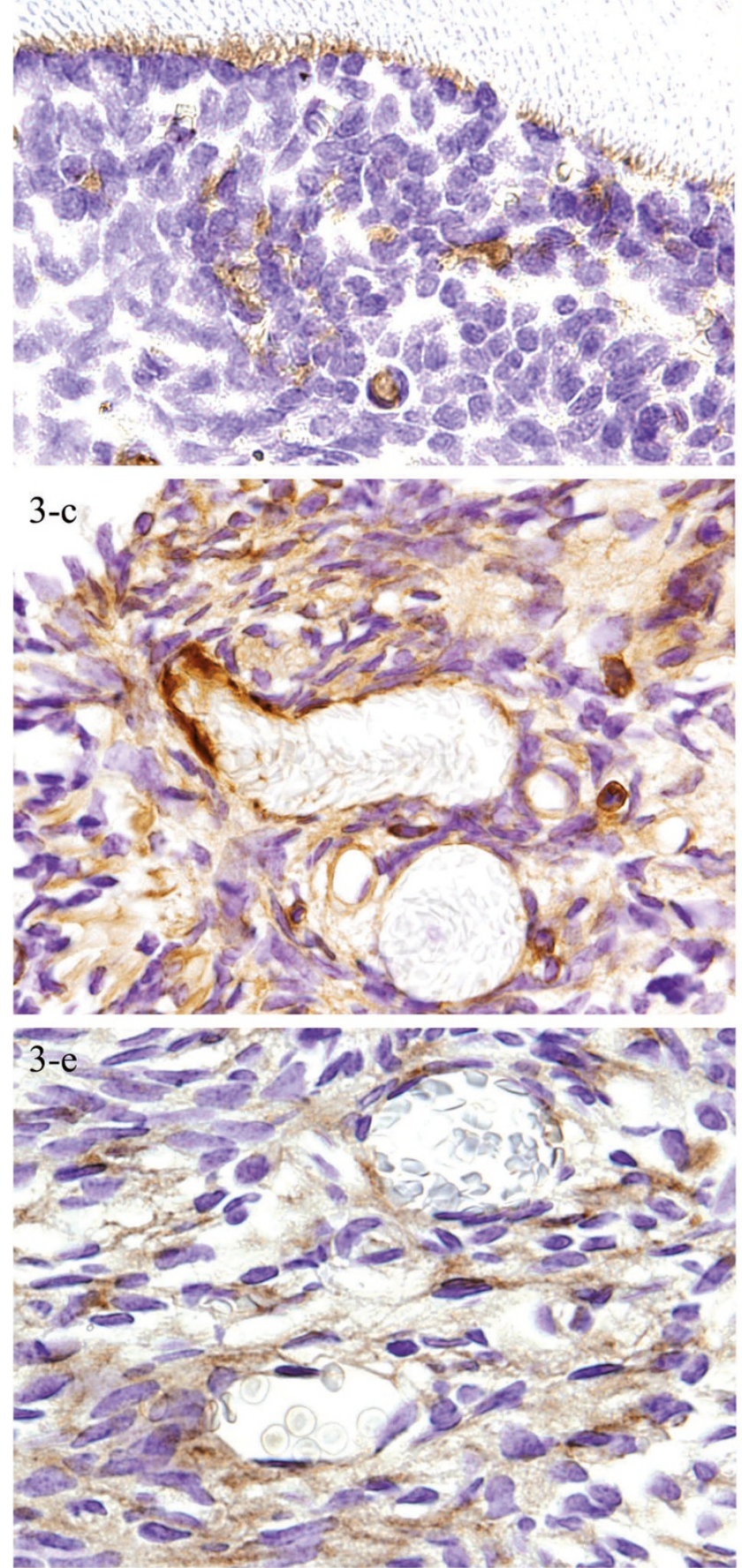

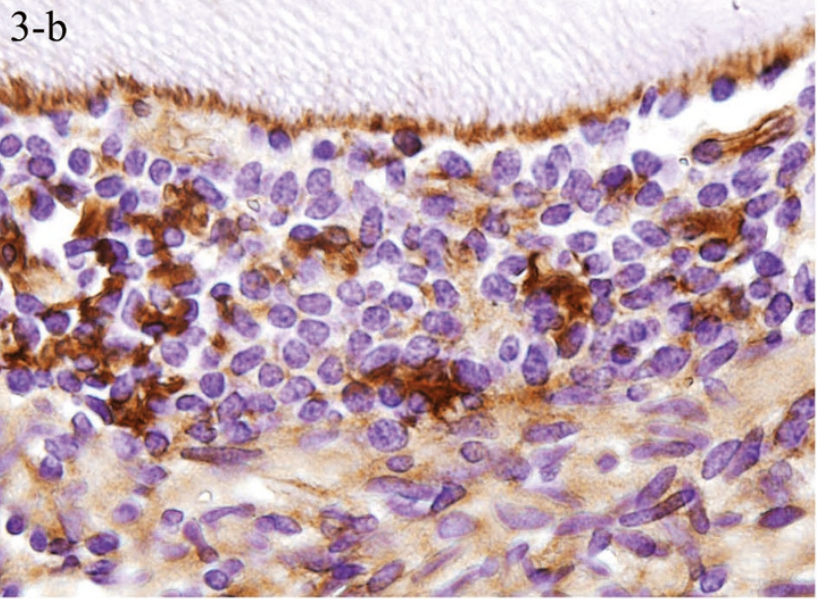

$3-d$

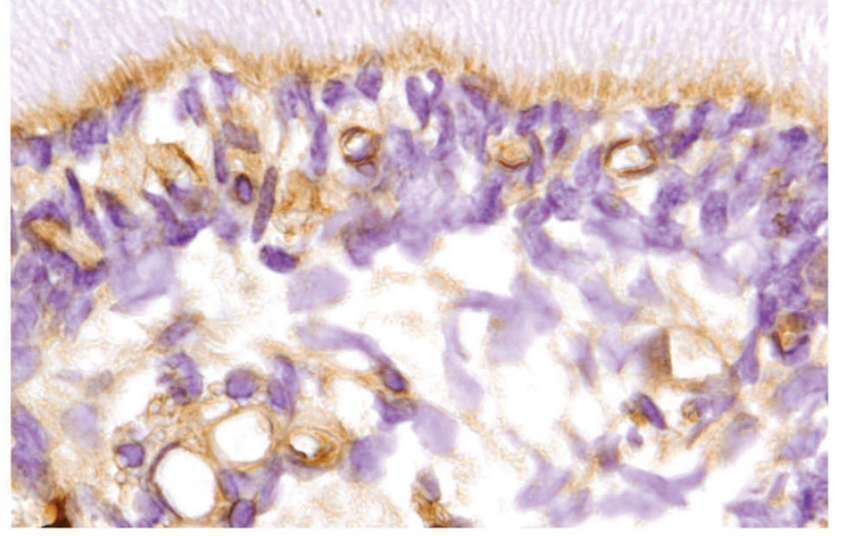

3-f

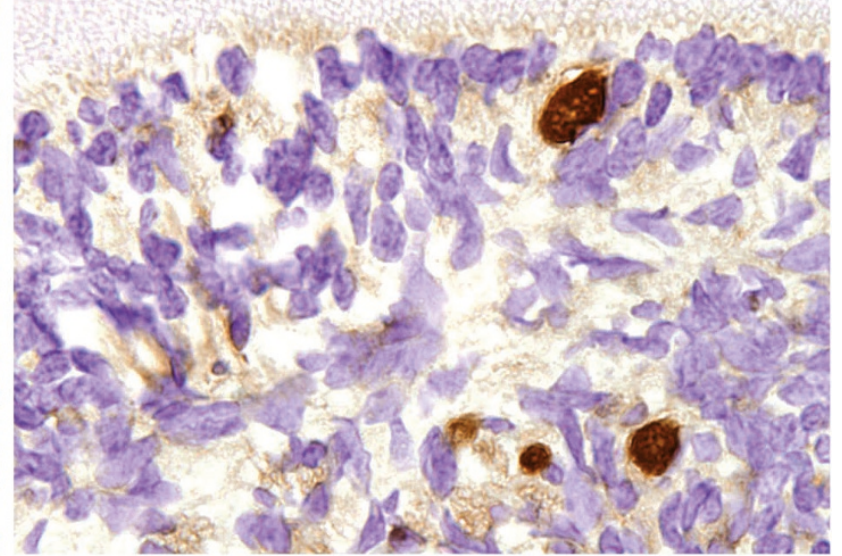

Fig. 3. Runx 2 expression in odontoblasts of the experiment group (30 minutes teeth separation) (a: 0 minute, b: 24 hours). Runx 2 expression in odontoblasts (d: 3 hours, f: 1 week) and pulp cells (c: 0 minute, e: 24 hours) of the experiment group ( 3 hours teeth separation) (magnification $\mathrm{x} 300$ ).

was seen in cytoplasm of some of odontoblasts and pulp cells and especially became stronger in cytoplasms of vessel endothelial cells (Fig. 4a). At 9 hours after wedge removal, ALP expression became stronger in cytoplasm of some of odontoblasts and vessel endothelial cells and especially in cytoplasms of pulp cells. At 24 hours after wedge removal, ALP strongly expressed in cytoplasms of odontoblasts, pulp cells and vessel endothelial cells (Fig. 4b).
At 3 days after wedge removal, though ALP expression was observed in cytoplasms of odontoblasts, pulp cells and vessel endothelial cells, the expression clearly became weaker as compared to 24 hours staining (Fig. 4c). At 1 week after wedge removal, though ALP expression was weakly seen in some of cytoplasms of odontoblasts, pulp cells and vessel endothelial cells, the expression became further weaker. 

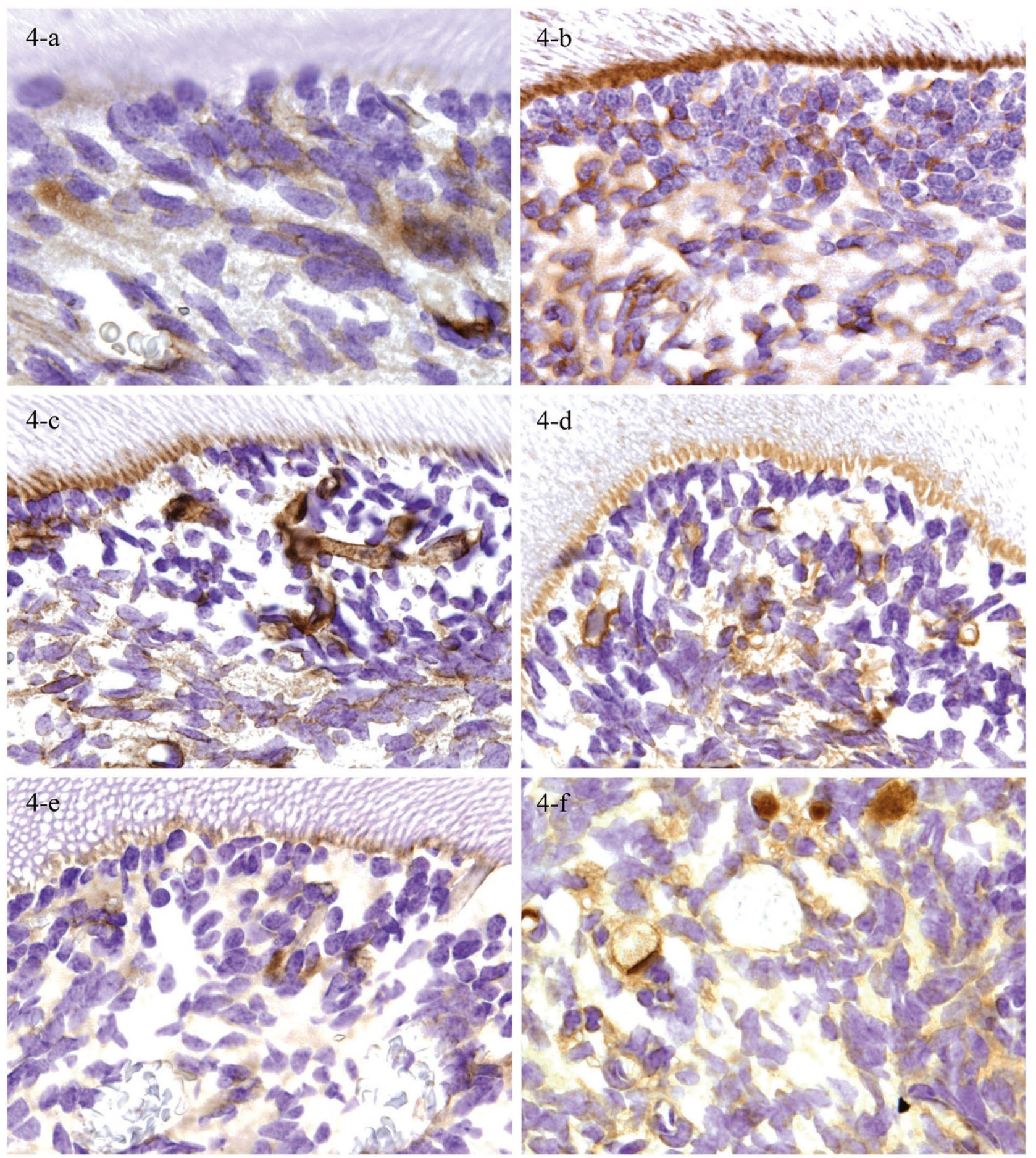

Fig. 4. ALP expression in odontoblasts of the experiment group (30 minutes teeth separation) (a: 3 hours, b: 24 hours c: 3 days). ALP expression in odontoblasts (d: 0 minute, e: 24 hours) and pulp cells (f: 1 week) of the experiment group ( 3 hours teeth separation) (magnification $\mathrm{x} 300$ ).

Group with 3 hours of teeth separation

At just after wedge removal, ALP expression was seen in some of odontoblast cytoplasm and vessel endothelial cells. ALP was especially expressed in cytoplasms of pulp cells (Fig. 4d). At $3 \mathrm{~h}$ after wedge removal, ALP expression was observed in cytoplasm of some of odontoblasts, pulp cells and vessel endothelial cells. At 9 hours after wedge removal, ALP expression became stronger in cytoplasm of some of odontoblasts and es- pecially in pulp cells and vessel endothelial cells. At 24 hours after wedge removal, ALP expression clearly became stronger in cytoplasms of odontoblasts, pulp cells and vessel endothelial cells (Fig. 4e). At 3 days after wedge removal, though ALP expression was seen in cytoplasms of some of odontoblasts and pulp cells, the expression became weaker in cytoplasm of vessel endothelial cells. At 1 week after wedge removal, though Runx2 expression was seen in cytoplasms of 
some of odontoblasts, pulp cells and vessel endothelial cells, the expression was weak (Fig. 4f).

\section{DisCUSSION}

Pulp is known to be activated with various traumatic stimulations even in healthy people. Thus regressive changes such as vacuolar degeneration and simple atrophy etc. occur in pulp cells. As a result of these changes, odontoblasts are also activated and formation of tertiary dentine is a well-known fact [14]. Histopathological researches investigating regressive as well as progressive changes of pulp cells are done from quite a long times [15]. And because mechanical stress is given to tooth during orthodontic movement, experimental histopathological studies have also been performed for a long time [16-18]. Some of these studies included electron microscopy views [19].

Recently knowledge on factors for regulation of differentiation of cells has been collected including hard tissue cells such as osteoblast differentiation. Sigehara et al. has investigated expression state of osteopontin, osteocalcin as well as Heat Shock Protein HSP [20]. Nakano et al. [10] investigated expression state of Runx2 in tooth root pulp, which is a representative differentiation factor not only for osteoblasts but also odontoblasts, by immunohistochemistry after orthodontic mechanical stress. They reported that because Runx2 expression increased in that tissue, activation of odontoblasts was also considered.

Currently occurrence of mechanical stress to circumferential tissue of tooth during tooth separation for preservative treatment is well known. Exposure of stress to periodontal tissues means movement of the tooth root. Thus movement of root shows exposure of stress to both apical foramen and lateral branches of vessels and nerves. In the current study, we prepared a similar experimental system using wedge for tooth separation and mechanical stress for pulp and examined Runx 2 expression by immunohistochemistry.

Runx2 belongs to transcription regulatory factor Runx family, which has 3 members named as Runx1, Runx 2 and Runx3 [16]. Runx2 has a role in cell differentiation and progression of cell cycle [17]. It has also played important roles for differentiation and growth of osteoblasts [18]. Similarly Runx2 is also thought to have role in differentiation and functional regulation of the hard tissue forming odontoblasts. However little is known about it [14]. And Runx2 is supposed to play important role not only in primary dentine formation but also in secondary as well as tertiary dentine formation. On the other hand, during differentiation of odontoblasts, ALP, an enzyme appeared at early stages of calcification, is a marker for activity level of pulp cells [19].

Before entering discussion of the current work, verification will be done for experiment system. The hypothesis was activation of odontoblasts with application of teeth separation and increased expression of hard tissue related factor Runx2 and experimental histopathological methods were used to test this hypothesis. That is, wedge was inserted at between moral teeth to separate them and pulp hard tissue related molecules then were examined with immunohistochemistry. However, examination of Runx 2 as well as ALP by immunohistochemistry is a qualitative method but not a quantitative one. Thus the reason for selection of mouse as experiment animal is to increase the number as much as possible to minimize the differences in immunohistochemistry between each animal. Therefore animal number was three in each time of each group. Teeth separation time was taken as 30 minutes, which is longest time for clinical application of such procedures. To prepare a strong mechanical stress, we also prepared a 3 hours teeth separation group. This experimental period ( 3 hours) is the time for attachment of the pressured root side to alveolar socket bone during orthodontic treatment with rubber application reported by Watanabe et al. [14]. And various time periods after application of mechanical stress were taken including just after the experiment through extending to 1 week period. Thus a total of 36 mice were used in the current study (Table 1).

The reason for selecting the distal buccal side of the upper left first molar for the experiment is due to results of the pre-experiment. Thus when same mechanical stress was applied, similar staining conditions were obtained both in the root and crown pulp. And when compared to other roots, utmost influence was seen on this root after loading. Examination of expression of hard tissue related factors such as Runx2 and ALP in the pulp is important after stimulation of various factors.

There are not so many researches regarding with differentiation of pulp cells after receiving traumatic stimulation. To the best of our knowledge, there is only one study reported by Wen et al. [1] regarding with ALP and Runx2 expression in pulp tissue. The authors did injury in rat pulp and examined Runx2 expression in pulp and tertiary dentine by immunohistochemistry. According to their report, at 1 day after the injury, Runx2 expression increased and then a decrease was found at 5 days and 1 week. Lee et al. reported increase of HSP-25 and ALP in cultured pulp cells after thermal stress [2].

And discussion will done regarding with results of the current experiment. First Runx2 immunohistochemistry showed weak expression in the control group pulp. This result is similar with reports of Nakano et al. $[10,21]$ and is compatible with normal response of the tooth for physiological mechanical stress such as mastication and tongue pressure. Next is the finding of the group with 30 minutes of teeth separation. As mentioned in the results, Runx 2 was determined in odontoblasts, vessel endothelial cells and pulp cells. The expression became maximum at 24 hours and gradually decreased and was almost similar with the control group at 1 week after the application of mechanical stress. This result shows stimulation effect of teeth separation stress on the pulp. It is considered from the point of odontoblast activation that Runx2 expression is increased for leading tertiary dentine formation [14]. Decrease of Runx2 expression within 1 week to the levels of the control group suggests that the stimulation is not so strong for maintenance of a long period. When compared with 3 hours of teeth separation, similar results were obtained. And 
ALP immunohistochemistry also showed weak expression in the control group pulp. This result is compatible with normal response of the tooth for physiological mechanical stress as for Runx 2 reaction. Next is the finding of the group with 30 minutes of teeth separation. As mentioned in the results, ALP also was determined in odontoblasts, vessel endothelial cells and proper pulp cells. The expression became maximum at 24 hours and gradually decreased and was almost similar with the control group at 1 week after the application of mechanical stress as for Runx2, suggesting that the stimulation is not so strong for maintenance of a long period. From expression results of Runx2 and ALP, it can be considered that though a temporary shift to tertiary dentine formation occurs at early periods of teeth separation, the expression state in the pulp becomes similar with the control group within one week after mechanical stress. In conclusion, when Runx2 and ALP expression are thought as a marker, it can be said that severe damage does not occur in the pulp during orthodontic clinical wedge application.

\section{REFERENCES}

1. Wen J, Tao R, Ni L, Duan Q and Lu Q. Immunolocalization and expression of Runx 2 in tertiary dentinogenesis. Hybridoma 2010; 29: 195-199.

2. Lee MW, Muramatsu T, J. Lee JH and Shimono M. Heat stress induces alkaline phosphatase activity and heat shock protein 25 expression in cultured pulp cells. Int Endod J 2008; 41: 158-162.

3. Watanabe T, Okafuji N, Nakano K, Muraoka R, Shimizu T, Kurihara S, Yamada K and Kawakami T. Periodontal tissue reaction to mechanical stress in mice. J Hard Tissue Biol 2007; 16: 71-74.

4. Watanabe T, Nakano K, Muraoka R, Shimizu T, Okafuji N, Kurihara S, Yamada K and Kawakami T. Role of Msx2 as a promoting factor for Runx2 at the periodontal tension sides elicited by mechanical stress. Eur J Med Res 2008; 13: 425-431.

5. Watanabe T, Okafuji N, Nakano K, Shimizu T, Kurihara $\mathrm{S}$, Yamada $\mathrm{K}$ and Kawakami T. Immunohistochemistry of the periodontal ligament fibroblasts in orthodontic tension sides. J Hard Tissue Biol 2009; 18: 175-180.

6. Muraoka R, Nakano K, Matsuda H, Tomoda M, Okafuji N, Kurihara S, Yamada K and Kawakami T. Immunohistochemical observation of heat shock proteins expression in mouse periodontal tissues due to orthodontic mechanical stress. J Hard Tissue Biol 2009; 18: 193-197.

7. Muraoka R, Nakano K, Kurihara S, Yamada K and Kawakami T. Immunohistochemical expression of heat shock proteins in the mouse periodotal tissues due to orthodontic mechanical stress. Eur J Med Res 2010; 15: 475-482.

8. Matsuda H, Muraoka R, Tomoda M, Nakano K, Okafuji N, Kurihara S, Yamada K and Kawakami T. Immunohistochemical observation of BMP in the mouse orthodontic periodontal tension sides. J Hard Tissue Biol 2009; 18: 181-184.

9. Matsuda H, Nakano K, Muraoka R, Tomoda M, Okafuji N, Kurihara S, Yamada K and Kawakami T. BMPs and related factors appearing in the mouse periodontal tissues due to orthodontic mechanical stress. J Hard Tissue Biol 2010; 19: 153-160.
10. Nakano K, Muraoka R, Tomida M, Matsuura S, Okafuji N, Siar CH and Kawakami T. Possibility of odontoblasts activity up-regulation due to orthodontic mechanical stress in mice. J Hard Tissue Biol 2010; 19: 13-16.

11. Villa PA, Oberti G, Moncada CA, Vasseur O, Jaramillo A, Tobon D and Agudelo JA. Pul-dentine complex changes and root resorption during intrusive orthodontic tooth movement in patients prescribed nabumetone. J Endod 2005; 31: 61-66.

12. Mostafa YA, Iskander KG and EI-Mangoury NH. Iatrogenic pulpal reactions to orthodontic extrusion. Am J Orthod Dentofac Orthop 1991; 99: 30-34.

13. Nixon CE, Saviano JA, King GJ and Keeling SD. Histomorphometric study of dental pulp during orthodontic tooth movement. J Endod 1993; 19: 13-16.

14. Chen S, Gu TT, Sreenath T, Kulkarni AB, Karsenty G and MacDougall M. Spatial expression of Cbfa1/Runx2 isoforms in teeth and characterization of binding sites in the DSPP gene. Connect Tissue Res 2002; 43: 338-344.

15. Xia SH, Ben CR, Niu ZY, Kohchi $T$ and Katayama I. Studies on the influence of composite resin filling material (Command Ultra fine) on the dental pulp. Meikai Daigaku Shigaku Zasshi 1990; 19: 349-355.

16. Durst KL and Hiebert SW. Role of Runx family members in transcriptional repression and gene silencing. Oncogene 2004; 23: 4220-4224.

17. Ito Y. Oncogenic potential of the RUNX gene family: Overview. Oncogene 2004; 23: 4198-4208.

18. Miyazaki T, Kanatani N, Rokutanda S, Yoshida C, Toyosawa S, Nakamura R, Takada S and Komori T. Inhibition of the terminal differentiation of odontoblasts and their transdifferentiation into osteoblasts in Runx2 transgenic mice. Arch Histol Cytol 2008; 71: 131-146.

19. Inoue T, Chen SH, Usuda J, Morohoshi $Y$ and Shimono M. Osteogenic activity of cells from dental pulp, periodontal ligament, bone marrow and muscle in vitro: an ultrastructural study and alkalinephosphatase activity. Bull Tokyo Dent Coll 1992; 33: 7-12.

20. Shigehara S, Matsuzaka K and Inoue T. Morphohistological change and expression of HSP70, osteopontin and osteocalcin mRNAs in rat dental pulp cells with orthodontic tooth movement. Bull Tokyo Dent Coll 2006; 47: 117124.

21. Nakano K, Muraoka R, Tomida M, Matsuura S, Okafuji $\mathrm{N}$, Siar $\mathrm{CH}$ and Kawakami T. Expression of HSP in dental root pulp cells due to experimental orthodontic mechanical stress. J Hard Tissue Biol 2009; 18: 127-130.

Received: June 20, 2011 / Accepted: July 11, 2011

Address for correspondence:

Toshiyuki Kawakami, PhD, Professor,

Hard Tissue Pathology Unit,

Matsumoto Dental University Graduate School of

Oral Medicine,

1780 Hirooka-Gobara,

Shiojiri,

399-0781 Japan

Phone: +81-263-51-2035

Fax: +81-263-51-2035

E-mail: kawakami@po.mdu.ac.jp 